\title{
Diode laser in the management of faun tail nevi
}

\section{Savitha Somaiah', Sana Mariam Sankey', Shashikumar Basavapura Madegowda², R Raghunatha Reddy ${ }^{1}$}

${ }^{1}$ Roots Institute of Dermatological Sciences - No.238, 1st H Main Rd, opposite Banaswadi, Balaji Layout, OMBR Layout, Banasawadi, Bengaluru, Karnataka 560043, India, ${ }^{2}$ Mandya Institute of Medical Science - Mysuru Main Road, Mandya 571401, Karnataka, India

Corresponding author: Sana Mariam Sankey, MD, E-mail: sanasankey@gmail.com

\begin{abstract}
Faun tail nevus is a rarely reported congenital cutaneous marker of an underlying spine or spinal cord anomaly characterized by the presence of a hypertrichotic patch affecting the lumbosacral region since birth. In addition to spinal dysraphism, it also affects the psychosocial life of the suffering patient. Herein, we report two cases of faun tail nevus, one with associated diastematomyelia. In both cases, cosmetic improvement was achieved with triplewavelength diode laser. This article aims to present this sparsely reported clinical entity and describe our experience in its management with diode laser.
\end{abstract}

Key words: Hypertrichosis; faun tail nevus; diode laser; triple wavelength

\section{INTRODUCTION}

Faun tail nevus is a localized patch of hypertrichosis affecting the lumbosacral region. It may be associated with an underlying spinal cord anomaly. We report two cases of faun tail nevus, one with underlying diastematomyelia and a cosmetic disability. Both experienced cosmetic improvement with a triplewavelength diode laser.

\section{CASE REPORT}

A 17-year-old female presented with excessive hair growth on the lumbosacral area since birth. She was born to a nonconsanguineous marriage, had an older sibling with no similar complaints, and had a normal vaginal delivery.

On local examination, a $12 \times 25 \mathrm{~cm}$ area of localized hypertrichosis with coarse dark terminal hair of varying lengths was present overlying the T10 to T12 vertebrae (Fig. 1). The underlying skin was normal. There were no other visible gross spinal defects. On further examination, she showed restricted forward bending with a normal gait and had achieved normal developmental milestones.

An MRI scan of the dorsolumbar spine revealed mild scoliosis with a convexity to the right, diastematomyelia at D11 to L2 level with a bony spur in the canal at the Dl2 to Ll level, and a conus at the L5 level, while the cervical spine and the CV junction were normal (Figs. 2 and 3).

A neurologist opinion was taken in view of the above, and the patient was advised conservative therapy as she had almost completed the growth curve and was asymptomatic.

The second patient presented to our OPD with similar complaints present since birth. No similar complaints were present in family members. On examination, a $15 \times 30 \mathrm{~cm}$ area of localized hypertrichosis was observed overlying the T9 to T12 vertebrae (Fig. 4). There were no visible gross defects, and an MRI scan was normal.

Because both patients were psychologically affected by their cosmetic disfigurements, laser hair removal

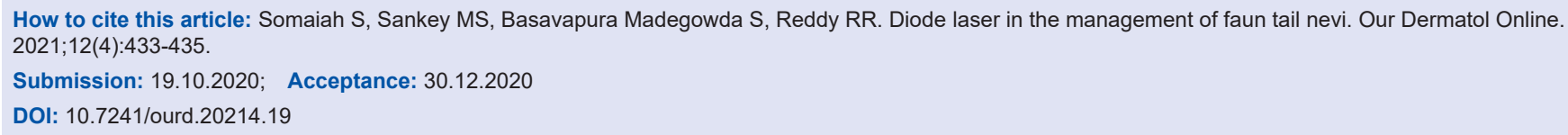




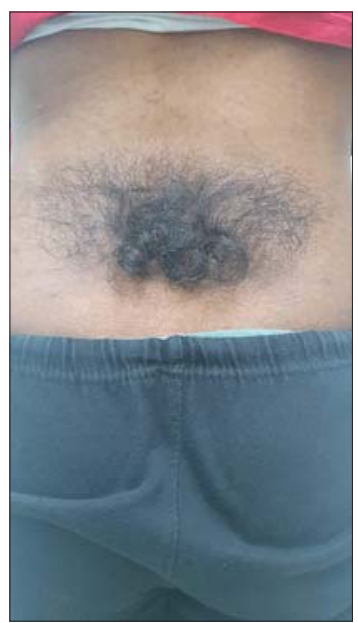

Figure 1: Clinical picture of faun tail nevus in the first patient.

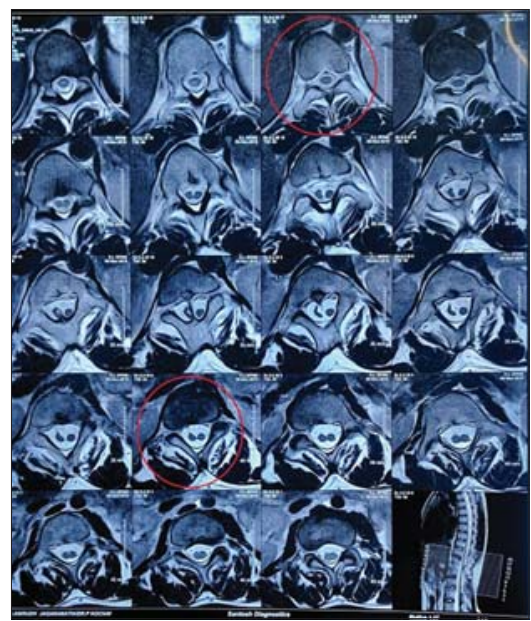

Figure 2: MRI scan showing a single and split spinal cord.

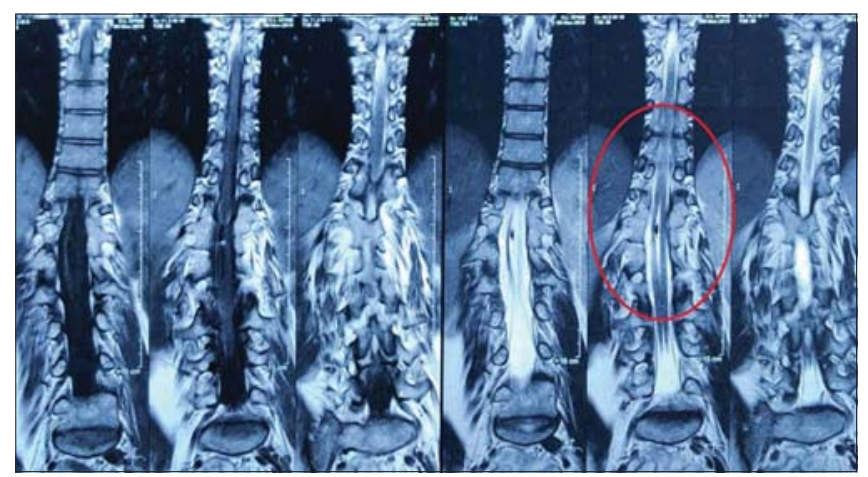

Figure 3: MRI scan showing diastematomyelia.

using a triple-wavelength diode laser was advised. Before initiating the treatment, the area was shaved and cleaned, and during the course of four treatments, the patients had not been using any other method of hair removal and followed the pre- and post-treatment instructions. The treatments were given monthly once. On the initial sitting, a total energy of $6 \mathrm{KJ}$, an energy

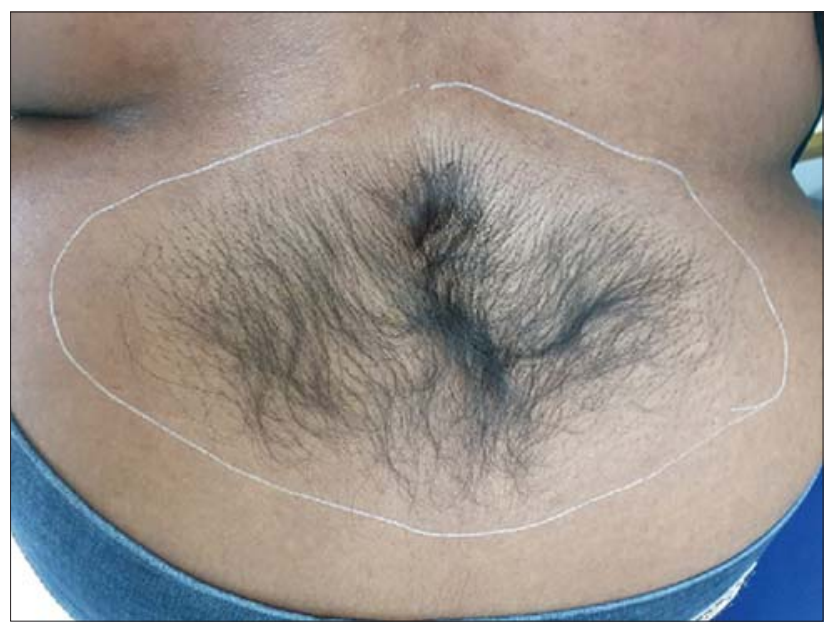

Figure 4: Clinical picture of a faun tail nevus in the second patient.

density of $7-8 \mathrm{~J} / \mathrm{cm}^{2}$, and a frequency of $8 \mathrm{~Hz}$ were used. On each sitting, the total energy was increased by $0.5 \mathrm{KJ}$. After four sittings, both patients had minor regrowth of thin and light hair. The patients are still under therapy.

\section{DISCUSSION}

Lumbar hypertrichosis may present itself in three forms: (a) simple nevoid hypertrichosis (abnormal hair away from the spine), (b) silky down (soft nonterminal hair at the midline), and (c) faun tail (a wide patch of coarse terminal hair several inches long at the midline) [1].

A faun tail is abnormal lumbosacral hypertrichosis characterized by a patch of coarse terminal hair usually several inches long. The word faun refers to the Italian deity in human form with horns, pointed ears, and a goat's legs and tail [1]. Failure of the caudal neuropore to close at the end of the fourth week of intrauterine life results in neural tube defects such as spinal dysraphism, which may also involve tissues overlying the spinal cord $[2,3]$.

Faun tail nevus is associated with spinal defects, most commonly spina bifida, intraspinal lipoma, dermal sinus, lipomeningomyeloceles, diastematomyelia, a tethered cord [4]. In our case, MRI revealed diastematomyelia, which is characterized by longitudinal splitting of the spinal cord into two parts. An osseous, cartilaginous, or fibrous septum in the central portion of the spinal canal produces a complete or incomplete sagittal division of the spinal cord into two hemicords. In occult cases of dysraphism, treatment is rarely required for a tethered cord or spinal instability, except for the cosmetic disfigurement [5]. 


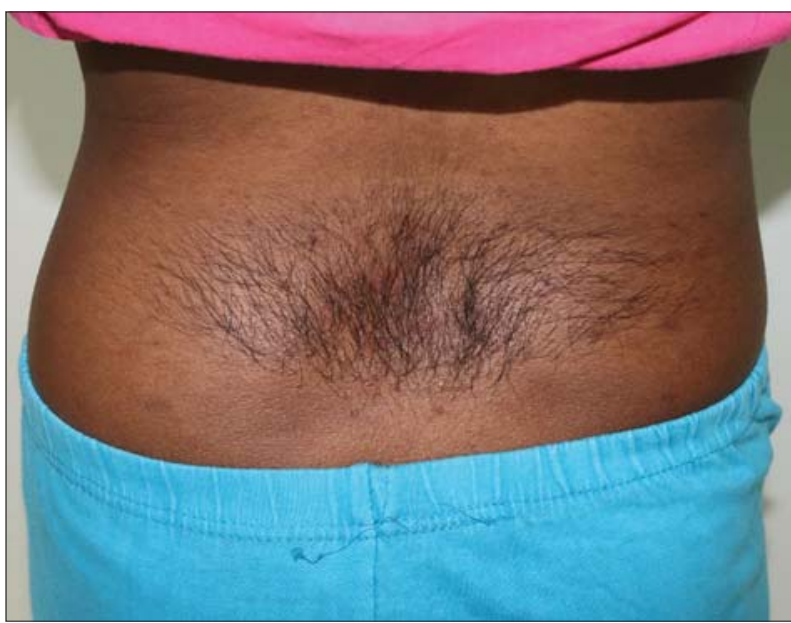

Figure 5: Effects after 4 sittings of diode laser in the first patient.

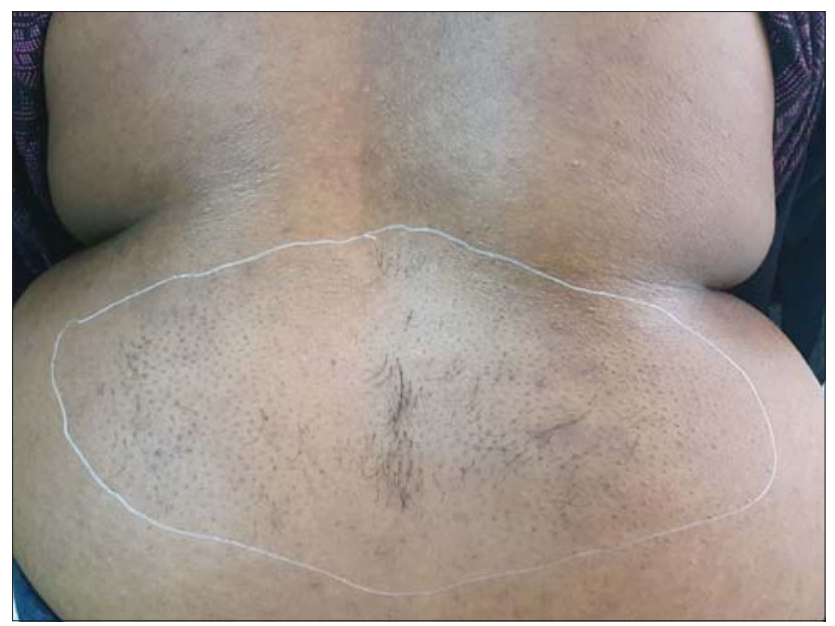

Figure 6: Effects after four sittings of diode laser in the second patient.

To achieve a better cosmetic appearance, various types of lasers have been found useful, for instance, the alexandrite laser, the ruby laser, the diode laser, the Nd:YAG laser [4], and intense pulsed light (IPL) [6]. The principle underlying these therapies is the selective absorption of laser energy by the melanin pigment in the hair follicle, which leads to its thermal destruction. Additionally, there is minimal absorption of energy by the surrounding tissues and, thus, skin damage does not happen [4]. Phototypes I-III require a broader choice of densities with a shorter length of the pulse, while the darker skin types (phototypes IV-VI) need lower densities and a longer duration of the laser pulse [7]. After the procedure, redness, burns, and pigmented lesions may be observed [8]. Both our patients had redness following each sitting and experienced a good cosmetic improvement after four sittings of triplewavelength diode laser therapy (Figs. 5 and 6).

\section{CONCLUSION}

This article aimed to present the rare cases of a faun tail nevus and our experience in improving their cosmetic aspect with a triple-wavelength diode laser.

\section{Consent}

The examination of the patient was conducted according to the principles of the Declaration of Helsinki.

The authors certify that they have obtained all appropriate patient consent forms, in which the patients gave their consent for images and other clinical information to be included in the journal. The patients understand that their names and initials will not be published and due effort will be made to conceal their identity, but that anonymity cannot be guaranteed.

\section{REFERENCES}

1. Podder I, Das A, Biswas S, Das NK. Faun tail nevus with neurofibroma: An uncommon cocktail. Indian J Paediatr Dermatol. 2015;16:84-6.

2. Sewell MJ, Chiu YE, Drolet BA. Neural tube dysraphism: Review of cutaneous markers and imaging. Pediatr Dermatol. 2015;32:161-70.

3. Atherton DI, Moss C. Neavi and other developmental defects. In: Burns T, Breathnach S, Cox N, Griffiths C., editors. Rook's Textbook of Dermatology. 7th ed, Vol. 15. Malden MA: Blackwell Publishing; 2004. p. 104-5

4. Kaptanoglu AF, Kaptanoglu E. Faun tail nevus and spinal dysraphism: Cosmetic improvement with alexandrite laser epilation. Ann Dermatol. 2011;23(Suppl 3):S296-8.

5. Kachewar SG, Sankaye SB. Diastematomyelia - A report of two cases. J Clin Diagn Res. 2014;8:RE01-2.

6. Ozdemir M, Balevi A, Engin B, Güney F, Tol H. Treatment of faun-tail naevus with intense pulsed light. Photomed Laser Surg. 2010;28:435-8.

7. Shirkavand A, Ataie-Fashtami L, Sarkar S, Alinaghizadeh MR, Fateh M, Zand N, et al. Thermal damage patterns of diode hairremoval lasers according to various skin types and hair densities and colors: A simulation study. Photomed Laser Surg. 2012;30:374-80.

8. Załęska I, Atta-Motte M. The effectiveness of diode laser $805 \mathrm{~nm}$ hair removal in groups of various ethnicity. J Med - Clin Res Rev. 2018;2:1-9.

Copyright by Somaiah Savitha, et al. This is an open access article distributed under the terms of the Creative Commons Attribution License, which permits unrestricted use, distribution, and reproduction in any medium, provided the original author and source are credited. Source of Support: Nil, Conflict of Interest: None declared. 